\title{
A Model for Advocacy and Community Participation in Research Thomas Gegeny*
}

\author{
Address: The Center for AIDS Information \& Advocacy, Houston, TX \\ Email: Thomas Gegeny* - tom@centerforaids.org \\ * Corresponding author $\ddagger$ Presenting author
}

from 2005 International Meeting of The Institute of Human Virology

Baltimore, USA, 29 August - 2 September 2005

Published: 8 December 2005

Retrovirology 2005, 2(Suppl I):P32 doi:I0.I I86/1742-4690-2-SI-P32

The Center for AIDS Information \& Advocacy (CFA) is a community-based, nonprofit organization that specializes in information, education, and advocacy for HIV/ AIDS research and treatment. Since 1995, The CFA has engaged the patient, research, and healthcare communities with unique programs, publications, and advocacy efforts designed to improve the healthcare of patients and the quality of their lives, as well as provide meaningful input into the design and process of research to help move forward the search for a cure. Through such efforts, researchers can interact with community to create awareness of clinical trials, as well as solicit input from community advisory boards organized with participation of The CFA. Several key CFA activities focus on developing ongoing relationships with the clinical and basic science research communities, both in Houston and nationally. These are: a biannual Basic Science Workshop (most recently held as a "Salvage Therapy Think Tank" cosponsored with the Forum for Collaborative HIV Research with additional support from Baylor College of Medicine); a literature-review journal, Research Initiative/Treatment Action! (RITA!), which is indexed in PubMed by the National Library of Medicine; a clinical trials directory for HIV/AIDS trials in the Houston area; and a weekly research and treatment newsletter sent by e-mail and fax to more than 600 subscribers internationally. Such activities foster important cross-communication between HIV researchers and the HIV/AIDS community and allow for better community participation in research. 